\title{
Visceral Afferents Directly Activate Catecholamine Neurons in the Solitary Tract Nucleus
}

\author{
Suzanne M. Appleyard, ${ }^{1}$ Daniel Marks, ${ }^{2}$ Kazuto Kobayashi, ${ }^{4}$ Hideyuki Okano, ${ }^{5}$ Malcolm J. Low, ${ }^{2,3}$ and \\ Michael C. Andresen ${ }^{1}$ \\ ${ }^{1}$ Department of Physiology and Pharmacology, ${ }^{2}$ Center for the Study of Weight Regulation and Associated Disorders, and ${ }^{3}$ Department of Behavioral \\ Neuroscience, Oregon Health \& Science University, Portland, Oregon 97239, ${ }^{4}$ Department of Molecular Genetics, Institute of Biomedical Sciences, \\ Fukushima Medical University, Fukushima 960-1295, Japan, and 5Department of Physiology, Keio University School of Medicine, Tokyo 160-8582, Japan
}

Brainstem $\mathrm{A}_{2} / \mathrm{C}_{2}$ neurons are catecholamine (CA) neurons within the solitary tract nucleus (NTS) that influence many homeostatic functions, including cardiovascular reflexes, food intake, and stress. Because NTS is a major interface between sensory visceral afferents and the CNS, NTS CA neurons are ideally suited to coordinate complex responses by their projections to multiple brain regions. To test how NTS CA neurons process visceral afferent information carried by solitary tract (ST) afferents, we identified CA neurons using transgenic mice expressing TH-EGFP (enhanced green fluorescent protein under the control of the tyrosine hydroxylase promoter) and recorded synaptic responses to ST activation in horizontal slices. ST shocks evoked large-amplitude, short-latency, glutamatergic EPSCs (ST-EPSCs) in $90 \%$ of NTS CA neurons. Within neurons, ST-EPSCs had constant latency, rarely failed, and depressed substantially at high ST frequencies, indicating that NTS CA neurons receive direct monosynaptic connections from afferent terminals. NTS CA neurons received direct ST inputs from only one or two afferent fibers, with one-half also receiving smaller amplitude indirect inputs. Up to $90 \%$ of ST shocks evoked action potentials in NTS CA neurons. However, transmission of sensory afferent information through NTS CA neurons critically depended on the expression of an A-type potassium current $\left(I_{\mathrm{KA}}\right)$, which when active attenuated ST-activated action potentials to a $37 \%$ success rate. The satiety peptide, cholecystokinin, presynaptically facilitated glutamate transmission in one-half of NTS CA neurons. Thus, NTS CA neurons are directly driven by visceral afferents with output being modulated by presynaptic peptide receptors and postsynaptic potassium channels.

Key words: tyrosine hydroxylase; vagus; NTS; food intake; cardiovascular; autonomic

\section{Introduction}

One of the earliest, histologically recognized cell groups in the CNS were the catecholamine (CA)-synthesizing neurons including those in the brainstem (Dahlstrom and Fuxe, 1964). The $\mathrm{A}_{2} / \mathrm{C}_{2}$ group of CA neurons lies within the solitary tract nucleus (NTS) and broadly impacts homeostatic regulation (Hollis et al., 2004). Despite this long record of investigation, the heterogeneous properties and dispersed distribution of these neurons have hindered a precise understanding of how they engage reflex systems (Kalia et al., 1985a,b; Baptista et al., 2005a). NTS is the major portal through which visceral afferent information concerning cardiovascular, respiratory, and gastrointestinal (GI) systems enters the brain (Andresen and Kunze, 1994; Saper, 2002). Furthermore, NTS CA neurons are activated by various afferent stimuli and they project extensively throughout the brain, including the hypothalamus, amygdala, nucleus accumbens, and dorsal

\footnotetext{
Received Aug. 1, 2007; revised 0ct. 3, 2007; accepted 0ct. 24, 2007.

This work was supported by National Institutes of Health Grants DK63040, DK066604, and HL41119. We thank Wilmon Grant for his technical assistance.

Correspondence should be addressed to Dr. Suzanne M. Appleyard at her present address: Department of Veterinary and Comparative Pharmacology and Physiology, College of Veterinary Medicine, Washington State University, P.0. Box646520,Pullman, WA 99164. E-mail: appleyas@vetmed.wsu.edu.

DOI:10.1523/JNEUROSCI.3502-07.2007

Copyright $\odot 2007$ Society for Neuroscience $\quad$ 0270-6474/07/2713292-11\$15.00/0
}

motor nucleus of the vagus (Riche et al., 1990; Wang et al., 1992; Petrov et al., 1993; Ueta et al., 2000; Travagli et al., 2006). Thus, NTS CA neurons are ideally situated to coordinate afferent signaling to multiple brain regions.

An example of a reflex pathway mediated by NTS CA neurons is the inhibition of food intake. Ingestion of a meal, gastric distension, and the satiety factor cholecystokinin (CCK) all increase c-fos expression in NTS CA neurons (Monnikes et al., 1997; Willing and Berthoud, 1997; Rinaman et al., 1998) and stimulate CA release at their projection sites (Buller and Day, 1996; Onaka, 2000; Ueta et al., 2000). Ablation of NTS CA neurons attenuates CCK-induced satiety (Rinaman, 2003). Although the most established satiety action of CCK is to increase vagal afferent discharge from the GI system to the NTS, direct injections of CCK into NTS also regulate gastric function (Talman et al., 1991; Moran et al., 2001). CCK facilitates glutamate release from sensory afferent terminals onto NTS proopiomelanocortin (POMC) neurons that are associated with feeding regulation (Appleyard et al., 2005) as well as centralis NTS neurons, where it preferentially affects neurons that are immunoreactive for TH (Baptista et al., 2005b). However, the effects of CCK on medial NTS CA neurons are unknown.

Propagation of afferent information by NTS CA neurons will depend on the translation of solitary tract (ST) afferent inputs 
into spike activity. Previous studies of NTS have recognized several cell groups on the basis of differences in intrinsic discharge properties and differential expression of potassium channels (Dekin and Getting, 1987; Moak and Kunze, 1993; Vincent and Tell, 1997). Therefore, determining how NTS neurons process visceral sensory afferent information is critical to understand what information is passed on to their downstream targets and how this pathway might be regulated. Here, we addressed these questions by identifying NTS CA neurons using a transgenic mouse and recording synaptic responses to afferent activation in horizontal brain slices. Our results show that processing of afferent information by NTS CA neurons depends on multiple factors, including innervation patterns, intrinsic membrane properties, and presynaptic modulation of glutamate release, providing key mechanisms to control transmission along this critical reflex pathway.

\section{Materials and Methods}

Breeding, housing, and genotyping of mice. Transgenic mice expressing enhanced green fluorescent protein under the control of the tyrosine hydroxylase promoter (TH-EGFP) (21-31 strain) (Matsushita et al., 2002) were maintained on either a DBA/2J (N8) or C57BL/6J (N5) background and genotyped for the presence of EGFP by PCR (Appleyard et al., 2005). They were housed on a $12 \mathrm{~h}$ light/dark cycle at ambient temperature in a murine specific pathogen-free facility of the Department of Comparative Medicine, Oregon Health \& Science University (Portland, OR). Chow (laboratory rodent diet no. 5001; PMI Nutrition International, St. Louis, MO) and water were provided ad libitum. All animal procedures were conducted with the approval of the Institutional Animal Care and Use Committee in accordance with the U.S. Public Health Service (PHS) Policy on Humane Care and Use of Laboratory Animals (PHS Policy) and the National Institutes of Health (NIH) Guide for the Care and Use of Laboratory Animals (NIH Guide).

TH immunofluorescent histochemistry. Mice (6-20 weeks) were anesthetized ( $2 \%$ tribromoethanol) and then perfused transcardially with $4 \%$ paraformaldehyde. After cryoprotection of the brainstem tissue with $20 \%$ sucrose, free-floating frozen sections were prepared using a sliding microtome. Sections were processed for immunofluorescence using standard techniques (Appleyard et al., 2005). Mouse monoclonal anti-TH (Santa Cruz Biotechnology, Santa Cruz, CA) was used at a final dilution of 1:10,000 (v/v). After rinsing, sections were incubated in biotinylated horse anti-mouse/rabbit IgG $(10 \mu \mathrm{g} / \mathrm{ml})$ (Vector Laboratories, Burlingame, CA) followed by Cy-3-conjugated streptavidin, 1:500 (v/v) (Jackson ImmunoResearch Laboratories, West Grove, PA). Highresolution confocal images were acquired using an Olympus (Tokyo, Japan) FluoView FV300 confocal laser-scanning microscope.

Horizontal NTS slices. Hindbrains of TH-EGFP mice (6-36 weeks of age) were prepared as described previously (Appleyard et al., 2005). Briefly, slices (250 $\mu \mathrm{m}$ thick; quasihorizontal plane) were cut with a sapphire knife (Delaware Diamond Knives, Wilmington, DE) mounted in a vibrating microtome (VT-1000S; Leica Microsystems, Bannockburn, IL). Horizontal slices contained a $2-5 \mathrm{~mm}$ length of the ST in the same plane as the NTS. Slices were submerged in a perfusion chamber and all recordings were performed in artificial CSF composed of the following (in mM): $125 \mathrm{NaCl}, 3 \mathrm{KCl}, 1.2 \mathrm{KH}_{2} \mathrm{PO}_{4}, 1.2 \mathrm{MgSO}_{4}, 25$ $\mathrm{NaHCO}_{3}, 10$ dextrose, $2 \mathrm{CaCl}_{2}$, bubbled with $95 \% \mathrm{O}_{2} / 5 \% \mathrm{CO}_{2}$ at $32-$ $35^{\circ} \mathrm{C}$ and $\mathrm{pH}$ 7.4. Osmolarity was adjusted to between 300 and 305 mOsm using dextrose. Neurons were recorded from NTS within \pm 200 $\mu \mathrm{m}$ of obex and medial to the ST using patch electrodes filled with a solution composed of the following (in $\mathrm{mm}$ ): $10 \mathrm{NaCl}, 130 \mathrm{~K}$-gluconate, 11 EGTA, $1 \mathrm{CaCl}_{2}, 2 \mathrm{MgCl}_{2}, 10$ HEPES, $2 \mathrm{NaATP}, 0.2 \mathrm{NaGTP}$, pH 7.3 and 295-299 mOsm. Patch electrodes, 2.0-4.0 M $\Omega$, were guided to neurons using both fluorescence and differential interference contrast (DIC) optics with infrared (IR) illumination (Axioskop FS2; Zeiss, Oberkochen, Germany). Voltage-clamp and current-clamp recordings were made with a Multiclamp 700B or Axoclamp 2A and pClamp 9 software (Molecular Devices, Union City, CA) with data sampled at $50 \mathrm{kHz}$ and filtered at $3 \mathrm{kHz}$ via an Axon $120 \mathrm{~A} / \mathrm{D}$ converter and pClamp9 software (Molecular Devices). Only neurons with stable holding currents not exceeding $100 \mathrm{pA}$ at $V_{\mathrm{H}}$ of $-60 \mathrm{mV}$ for the $15 \mathrm{~min}$ control period were studied further. Input resistance was monitored throughout recordings and experiments were discarded if series or input resistance became unstable. No leak subtractions or series resistance compensations were performed. Membrane potential values reported are corrected for liquid junction potential $(-14 \mathrm{mV})$.

Measurement of synaptic currents. Synaptic currents were triggered with an ultrafine concentric bipolar stimulating electrode (125 $\mu \mathrm{m}$ outer diameter; F. Haer, Bowdoinham, ME) placed on the ST 1-5 mm from the recording electrode. Bursts of five shocks $(50 \mathrm{~Hz})$ were generated at $3 \mathrm{~s}$ intervals and delivered from an isolated programmable stimulator (Master-8; AMPI). Latency was measured for the first of each burst of five ST-EPSCs. Latency jitter was calculated as the SD of $>30$ ST-EPSCs and used to classify neurons as either directly contacted by ST afferents (monosynaptic jitter $<200 \mu$ s) (i.e., second order) or by ST polysynaptic pathways (jitter $>200 \mu$ s) (i.e., higher order) (Doyle and Andresen, 2001).

ST stimulus intensity-recruitment relationships. ST shock intensity was gradually increased until an EPSC was evoked. The onset of a suprathreshold response was all-or-none as expected from activation of a single ST axon. Increases in shock intensity often did not further alter synaptic response amplitudes, a finding consistent with synaptic responses mediated by activation of an individual axon (Andresen and Yang, 1995; Bailey et al., 2006a). In some neurons, additional synaptic inputs were recruited with additional increases in shock intensity up to a maximum of $0.5 \mathrm{~mA}$. These additional inputs were analyzed separately by measuring each event with a narrow time window for each monosynaptic and wider time window around each polysynaptic event. The presence of additional ST-synced events indicated convergent inputs. Failures were counted when an ST shock was not followed by a synaptic event within the appropriate time window. Failure rates were unaltered by increases in shock intensity. Failure rates were expressed as a percentage of successful events divided by the number of trials using a minimum of 30 trials. Shock intensity was set at two times threshold for subsequent testing.

Measurement of potassium currents. Transient $I_{\mathrm{KA}}$ and sustained outward currents $\left(I_{\mathrm{KV}}\right)$ were evoked by depolarizing voltage steps (Bailey et al., 2002). $I_{\mathrm{KA}}$ was calculated as the peak early transient current $(\sim 5-10$ $\mathrm{ms}$ after voltage step and after the capacitive transient) minus the late $I_{\mathrm{KV}}$ current (measured $500 \mathrm{~ms}$ after voltage step). The voltage dependence of activation of these currents was assessed using a $200 \mathrm{~ms}$ conditioning step to $-100 \mathrm{mV}$ followed by test steps $(500 \mathrm{~ms})$ to voltages ranging from -100 to $0 \mathrm{mV}$. Voltage-dependent inactivation was induced with conditioning steps $(200 \mathrm{~ms}$ ) ranging from -100 to $0 \mathrm{mV}$ that were followed by a test step $(500 \mathrm{~ms})$ to $0 \mathrm{mV}$. In a limited series, the $I_{\mathrm{KA}}$ antagonist 4-aminopyridine (4AP) ( $5 \mathrm{~mm}$ ) was introduced to the perfusate to separate $I_{\mathrm{KA}}$ from $I_{\mathrm{KV}}$.

Action potential responses. The discharge properties of NTS CA neurons were assessed with depolarizing and hyperpolarizing steps of constant current while recording in current-clamp mode. Depolarizing current steps evoked trains of action potentials (APs). Current steps to -100 $\mathrm{mV}$ for $500 \mathrm{~ms}$ conditioned neurons by removing voltage-dependent inactivation from $I_{\mathrm{KA}}$. Synaptically evoked APs were tested in current clamp using the same ST burst stimulation protocols described above.

Miniature EPSCs. In gap-free mode (AxoClamp), miniature EPSCs (mEPSCs) were recorded in voltage clamp in the presence of $1 \mu \mathrm{M}$ TTX and $2 \mu \mathrm{M}$ gabazine. Events were collected over several minutes in control and then during drug exposure for comparison. Analysis was performed off-line using pClamp (Molecular Devices) and Mini Analysis (version 5.0; Synaptosoft, Decatur, GA).

Drugs. NBQX was obtained from Tocris Cookson (Ballwin, MO). Gabazine, 4AP, and CCK were obtained from Sigma (St. Louis, MO) and TTX from Alomone Labs (Jerusalem, Israel).

Statistical analyses. All data are presented as means \pm SEM. Statistical comparisons used either unpaired Student's $t$ test, repeated-measures ANOVA, or one-way ANOVA followed by Fisher's protected least significant difference post hoc analysis. Kolmogorov-Smirnov (K-S) nonparametric analysis was used to compare cumulative distributions of mEPSC 
amplitudes and frequencies. Values of $p<0.05$ indicated significant differences.

\section{Results}

\section{EGFP colocalizes with TH} immunoreactivity in TH-EGFP mice Catecholamine neurons were identified using a transgenic mouse that expresses EGFP (enhanced green fluorescent protein) under the control of tyrosine hydroxylase promoter (TH-EGFP), the ratelimiting enzyme for synthesis of CA (Sawamoto et al., 2001; Matsushita et al., 2002). TH-EGFP neurons were widely distributed throughout the NTS including the medial, intermediate, commissural, and ventral subdivisions (Paxinos, 2001). We found that TH immunostaining extensively $(>85 \%)$ colocalized with EGFP fluorescence in the NTS of TH-EGFP mice (Fig. $1 A-C$ ). This distribution of EGFP neurons closely resembles $\mathrm{TH}$ immunohistochemically identified in neurons in the mouse and rat (Kalia et al., 1985a,b; Hollis et al., 2004). Our results show EGFP expression in TH-EGFP mice specifically localizes to TH neurons in the NTS as has been shown for other brain regions (Sawamoto et al., 2001) and confirms the usefulness of this transgenic mouse to identify CA neurons.

\section{Visualization of NTS CA neurons in horizontal slices for recording}

Visualization of the EGFP signal in horizontal slices (Fig. 1D,E) directed the recording electrode specifically to $\mathrm{TH}$ neurons. Placing the ST stimulating electrode 1-5 $\mathrm{mm}$ away from the recorded neurons, permitted remote activation of ST axons and minimized the likelihood of focal activation of local interneurons or interconnecting fibers. The borders of the cell bodies of individual neurons were identified at higher magnification using IR DIC and matched with fluorescence of EGFP (Fig. $1 F, G$ ). No patterns in cell morphology of TH-EGFP neurons provided sufficient visual clues for their identification.

\section{Solitary tract activation evokes glutamatergic, monosynaptic EPSCs in most NTS CA neurons}

NTS CA neurons had an average input resistance of $708 \pm 40$ $\mathrm{m} \Omega$. ST shocks evoked time-invariant EPSCs in nearly every NTS CA neuron. Typically, ST-EPSCs were large, their waveforms varied minimally in amplitude, time, or shape, and ST shocks rarely failed to evoked an ST-EPSC (Fig. 2A). These ST-EPSC properties are characteristic of direct, monosynaptic connections with ST afferents and indicate that most NTS CA neurons are secondorder neurons in these cranial afferent pathways.

In contrast, in a very small population of NTS CA neurons, repeated shocks evoked only highly variable ST-EPSCs (Fig. 2 B). ST-evoked, variable latency synaptic responses had moderate amplitudes with the frequent synaptic failures that are characteristic of indirect polysynaptic pathways (Fig. $2 B$ ). Such higher- order NTS CA neurons often displayed multiple synaptic inputs with unique latencies from the ST shocks (Fig. 2 B, labeled 1 and 2 ) that were distinguished from spontaneous events (Fig. $2 B$, event 3 ) by their repeated appearance and synchronized timing to ST activation. These high-jitter, ST-synched inputs, thus, represent separate, indirect pathways activated by ST afferents that converge to summate on single NTS CA neurons.

Three measures of synaptic performance distinguished direct from indirect ST contacts onto NTS CA neurons: (1) synaptic jitter $<200 \mu \mathrm{s}$, (2) an absence of synaptic failures at $50 \mathrm{~Hz}$ shock frequency, and (3) consistent EPSC amplitude and waveform. In $90 \%$ of recorded NTS CA neurons (65 of 73 neurons), the STEPSCs characteristics were consistent with monosynaptic transmission (Fig. 2C). We found no evidence of direct ST inputs in the remaining NTS CA neurons. It is possible that some direct fiber connections might be lost by cutting afferent fibers leaving the plane of the slice during preparation, and, therefore, our methods may underestimate the proportion of NTS CA neurons that receive direct connections. Alternatively, the NTS CA neurons lacking direct ST inputs (10\%) may represent a unique population of NTS CA neurons that only received afferent information indirectly via other excitatory NTS interneurons. Regardless, the neurons that receive only indirect inputs allowed us to com- 
A
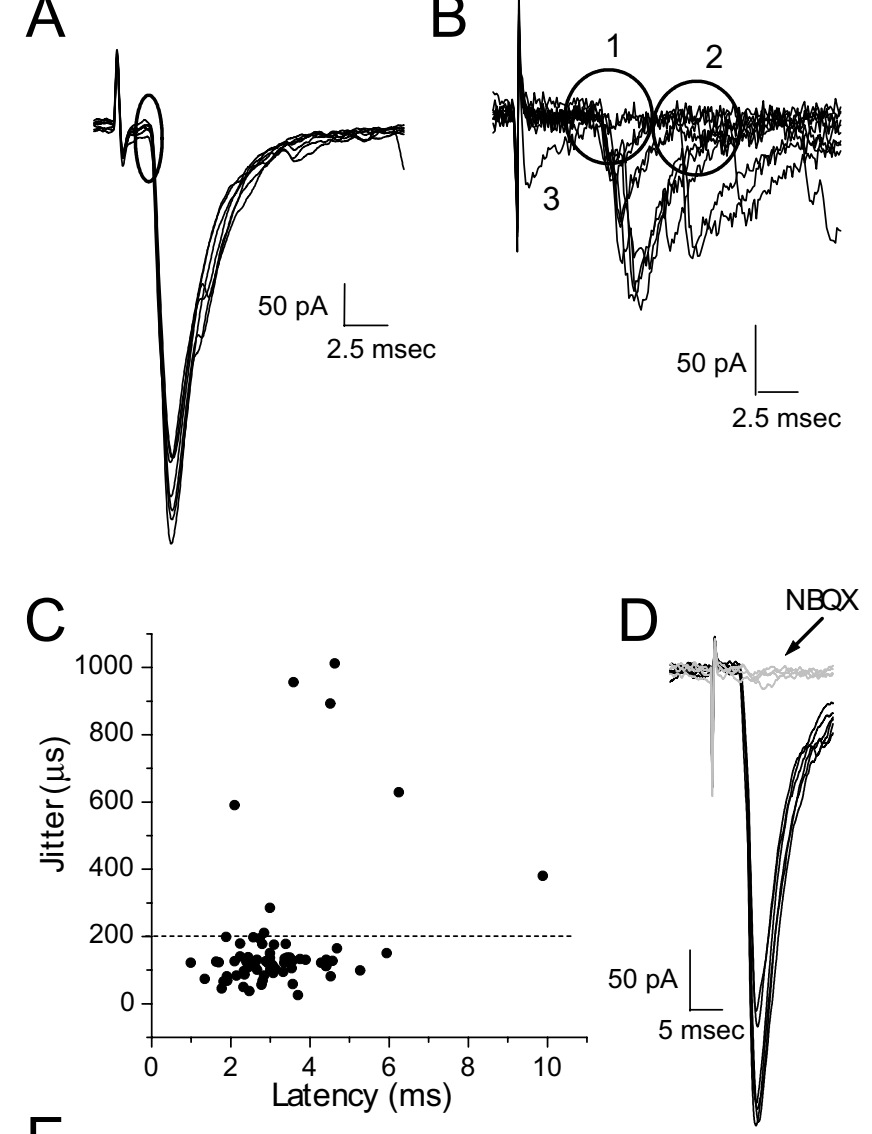

E

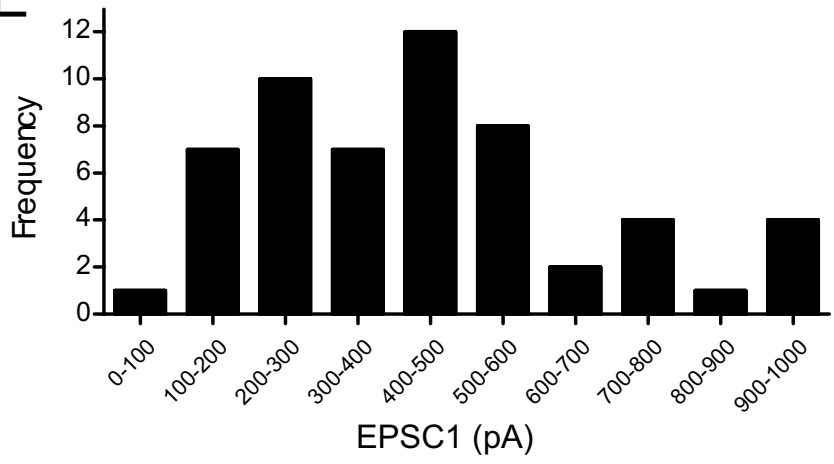

Figure 2. ST evoked NTS synaptic responses in NTSCA neurons. A, ST activation evoked a low-jitter (i.e., monosynaptic) EPSC in NTS CA neurons. Ten successive EPSCs are overlaid. $V_{M}=-60 \mathrm{mV}$. ST shocks evoked a short-latency EPSC with high reliability (latency, $2.3 \mathrm{~ms}$; jitter, $96 \mu \mathrm{s}$; and no observed failures at $50 \mathrm{~Hz}$ ST stimulation). $\boldsymbol{B}$, In some NTS CA neurons, ST activation evoked only high-jitter (i.e., polysynaptic) EPS(s. Ten successive EPSCs are overlaid. $V_{M}=-60 \mathrm{mV}$. ST shocks evoked responses with high variability in latency and amplitude. Two clusters of events (onsets circled, labeled 1 and 2) occurred at different times (event 1: latency, $4.6 \mathrm{~ms} ;$ jitter, $892 \mu \mathrm{s}$ ). Note that flat lines within circle 1 represent failures of that event. In the case of failure of event 1 , event 2 was unaffected and vice versa. The event labeled 3 is a spontaneous synaptic event that never reoccurred and thus is not ST shock related. C, Relationship between latency and jitter (SD of latency) for all NTS CA neurons. Note that nearly all (90\%) NTSCA neurons had second-order, monosynaptic ST response characteristics $<200$ $\mu$ s; broken line). Latency was not strictly related to path order. D, NBQX (10 $\mu \mathrm{m})$ completely blocked the ST-EPSCs in this representative neuron $(n=8)$. The circles in $A$ and $B$ represent the time windows used for analysis of the onset of each ST-EPSC response. $\boldsymbol{E}$, Histogram showing the distributions of ST-EPSC amplitudes in NTS CA neurons.

pare the properties of the responses produced by direct versus indirect inputs. The average amplitude of direct ST-EPSCs was substantially larger ( $p<0.001$, Student's $t$ test) than those evoked by indirect connections $(443 \pm 28.5 \mathrm{pA}, n=63$ for direct vs $139 \pm 14.2 \mathrm{pA}, n=7$ for indirect). Direct connections never failed ( $0 \%$ failure rate), whereas indirect connections failed to respond to $23 \pm 4.4 \%$ of shocks. The non-NMDA glutamate receptor antagonist NBQX $(10 \mu \mathrm{M})$ completely blocked all STevoked EPSCs (Fig. 2D) $(n=8)$. A broad range of amplitudes of ST-EPSCs were evoked in CA neurons with $>500 \mathrm{pA}$ amplitude EPSCs commonly seen (Fig. 2E).

\section{Stimulus intensity-response relationship of ST-evoked synaptic transmission}

Increasing the stimulus shock intensity can recruit afferent fibers with different thresholds or reach fibers displaced from the location of the stimulus electrode (axon threshold and spatial recruitment, respectively). To characterize the ST-synced synaptic inputs to NTS CA neurons, the shock intensity was increased in small increments to probe the relationship between shock intensity and the amplitude, timing, and form of synaptic events. At the lowest levels, increments in shock intensity were without effect until a threshold was reached and an EPSC was evoked. However, above this threshold level, additional increases in shock intensity often altered neither the EPSC amplitude nor its waveform even with severalfold increases in intensity (Fig. $3 A$ ). When the stimulating electrode was moved a small distance off the ST, shocks no longer evoked EPSCs (data not shown). The all-or-none nature of the evoked EPSC across a wide range of shock intensity values is consistent with the remote activation of a single axon whose terminals released glutamate onto the NTS CA neuron. Such neurons showed no evidence of recruitment of additional directly connected fibers within the NTS. Thus, in such NTS CA neurons, we failed to observe the graded increase in amplitude with increasing shock intensity that would indicate a progressive recruitment of added inputs from converging fibers as seen in the hippocampus (Buzsaki and Chrobak, 1995).

According to the shock intensity-recruitment relationships for 26 NTS CA neurons, ST stimulation evoked monosynaptic inputs to $90 \%$ (24 of 26) of these neurons, and thus NTS CA neurons were overwhelmingly classified as second-order NTS neurons. One-half of these second-order NTS CA neurons (12 of 24) received additional, ST-evoked, polysynaptic inputs. Nearly one-half of NTS CA second-order neurons ( $41 \%$ or 10 of 24) received only one monosynaptic input (Fig. $3 A$ ) and the rest (14 of 24) received multiple unique, monosynaptic inputs that each met monosynaptic criteria (threshold intensity, latency, jitter, and failures). In most (12 of 14) cases, these were dual ST-EPSC inputs and increasing shock intensity above the threshold for the first, lower-threshold input recruited a second low-jitter STEPSC with a unique, well defined shock intensity threshold (Fig. $3 B)$. The two inputs had different latencies, jitter values, and waveforms consistent with two independent, direct ST contacts, and the activation of the second input did not alter the amplitude or waveform of the first (Fig. 3B). Such observations are interpreted as arising from two individual ST afferent axons that converge to synapse directly on the same NTS CA neuron.

In rare cases $(n=2)$, NTS CA neurons received only indirect synaptic inputs (Fig. 4A) and were classified as higher-order NTS neurons (data not shown) (similar to Fig. 2B). More commonly, such polysynaptically ST-coupled synaptic events accompanied single ( 7 of 10) or multiple ( 3 of 14) monosynaptic inputs onto second-order NTS CA neurons (Fig. 4). Polysynaptically routed EPSCs displayed characteristically variable timing and often failed to appear after ST shocks. Interestingly, however, the shock intensity-recruitment relationships for indirect inputs closely resembled the profiles for direct ST-EPSCs and displayed abrupt, 

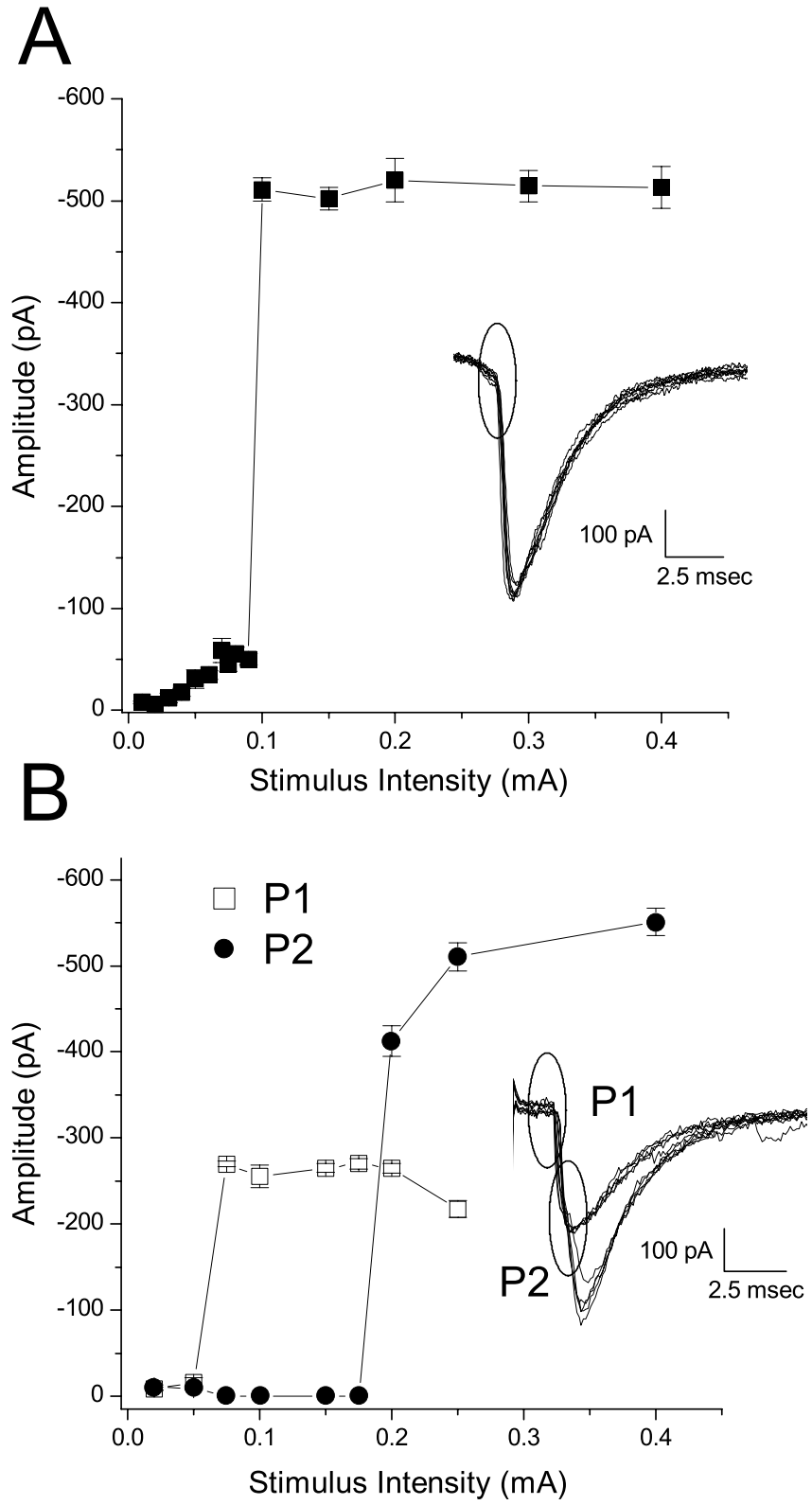

Figure 3. Stimulus intensity-response profiles for ST-evoked synaptic transmission. Graded increments in shock intensity delivered to ST produced profiles for the recruitment of each synaptic event. The majority of NTS CA neurons receive monosynaptic inputs (jitter, $<200 \mu \mathrm{s}$ ) from one or two ST afferents. $A$, Stimulus intensity-response relationship for an NTS CA neuron receiving one monosynaptic ST input (latency, $3.1 \mathrm{~ms}$; jitter, $90 \mu \mathrm{s}$ ). Low-intensity stimuli elicited no synaptic response and increasing shock intensity fourfold above threshold had no effect on EPSC amplitude, evidence that ST shocks activated a single axon of constant electrical threshold to trigger the EPSC. Inset are traces of EPSCs elicited by suprathreshold stimulation. The oval indicates the time window for latency analysis. $\boldsymbol{B}$, Stimulus intensity-response relationship for an NTS CA neuron directly receiving two monosynaptic ST inputs. The inset displays representative traces of EPSCs from this neuron showing the two individual peaks (input 1: latency, $2.0 \mathrm{~ms}$; jitter, $121 \mu \mathrm{s}$; input 2: latency, $2.6 \mathrm{~ms}$; jitter, $122 \mu \mathrm{s})$. Traces were evoked by increases in stimulus shock intensity and displayed as overlapping traces. The EPSC evoked as input 1 was triggered at lower threshold shock intensity than input 2. As shock intensity was increased, input 2 was recruited as a summed event. Note that input 2 amplitude is plotted as that summed event. If a subtraction is performed, input 1 and input 2 appear to have nearly equal amplitudes but are distinguished by latency and threshold shock intensity. Note that neither input failed to occur when stimulus intensity exceeded threshold for both input 1 and input 2. The ovals ( 1 and 2 ) indicate the time windows for latency analysis of the two events. This pattern of stimulus intensity-response profile indicating two direct, monosynaptic connections was found in one-half of all second-order NTS CA neurons (i.e., these neurons had dual, direct ST contacts). Error bars indicate SEM.
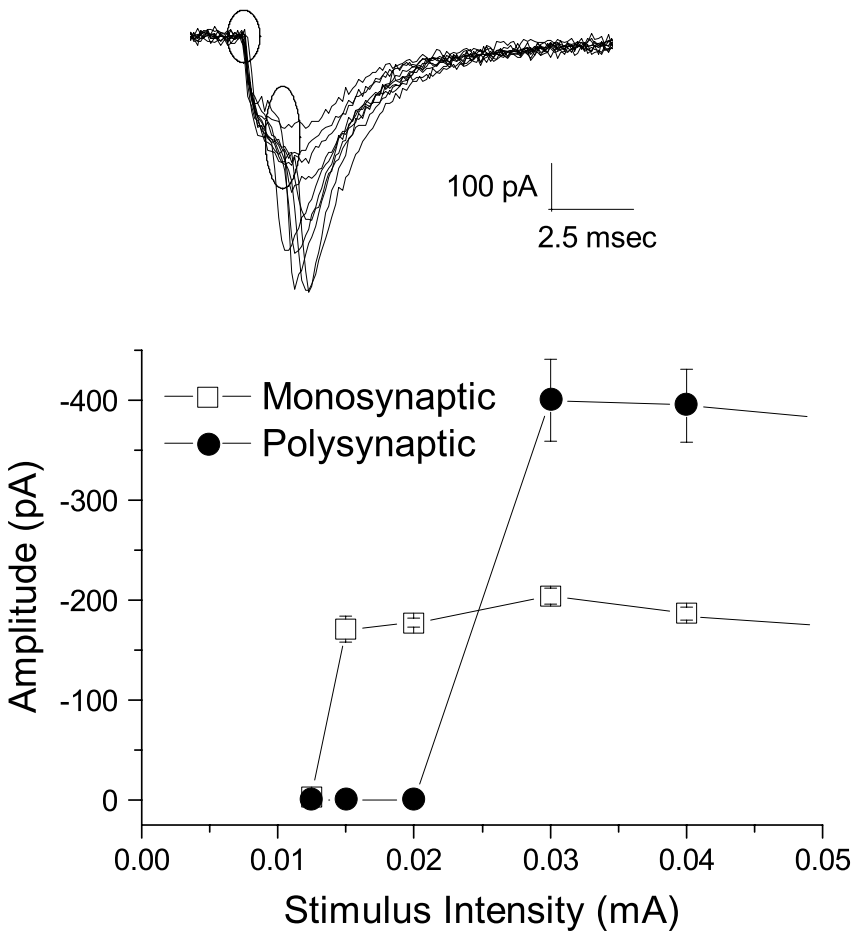

Figure 4. Stimulus intensity-response profile for ST-evoked mixed monosynaptic and polysynaptic inputs. Input 1 was monosynaptic (latency, 2.2; jitter, $118 \mu \mathrm{s}$ ), and input 2 was polysynaptic (latency, 3.4; jitter, $387 \mu \mathrm{s}$ ). The top part displays traces of EPSCs elicited by stimulus shocks that were suprathreshold for both inputs. The ovals mark the two time windows for analysis of the onset of the responses. Event amplitudes did not change with ST shock intensities severalfold above threshold (bottom plot). Note that failures of the polysynaptic input pathway produced lower amplitude EPSCs to input 1 despite stimulus shock intensities severalfold above threshold for either input. Error bars indicate SEM.

all-or-none thresholds with constant suprathreshold mean amplitudes over a wide range of shock intensity. EPSC amplitudes to indirect inputs tended to have larger variability (Fig. 4) and failures were present even at very high, suprathreshold intensities. Because indirect inputs often had smaller amplitudes, some may have been masked from detection by the much larger currents evoked by direct inputs. Therefore, our methods may underestimate the proportion of NTS CA neurons (46\%) receiving both direct and indirect ST-evoked synaptic inputs.

\section{Frequency-dependent depression of ST-EPSCs}

Frequency-dependent depression (FDD) is a prominent characteristic of synaptic transmission found at direct ST-NTS synapses (Doyle and Andresen, 2001). Trains of five shocks evoked consistent patterns of low-jitter, ST-EPSCs with amplitudes that progressively depressed within each burst but recovered fully during the interval between bursts ( $3 \mathrm{~s}$ ). The EPSC evoked by the second shock (EPSC2) was markedly smaller than EPSC1. On average for such direct ST-EPSCs, this progressive depression in amplitude reached a maximum within the burst because EPSC 3, 4, and 5 were not significantly different (Fig. $5 A, C)(p<0.05)$. In contrast, no FDD was discernable with indirect, ST-evoked inputs (Fig. $5 B, C)(p>0.05)$. As a result of these differences in the FDD, the amplitudes of direct EPSCs approached those of indirect ST-EPSCs late in the shock burst and the average amplitudes of EPSC5 were similar across all NTS CA neurons late within the bursts (Fig. 5C). 

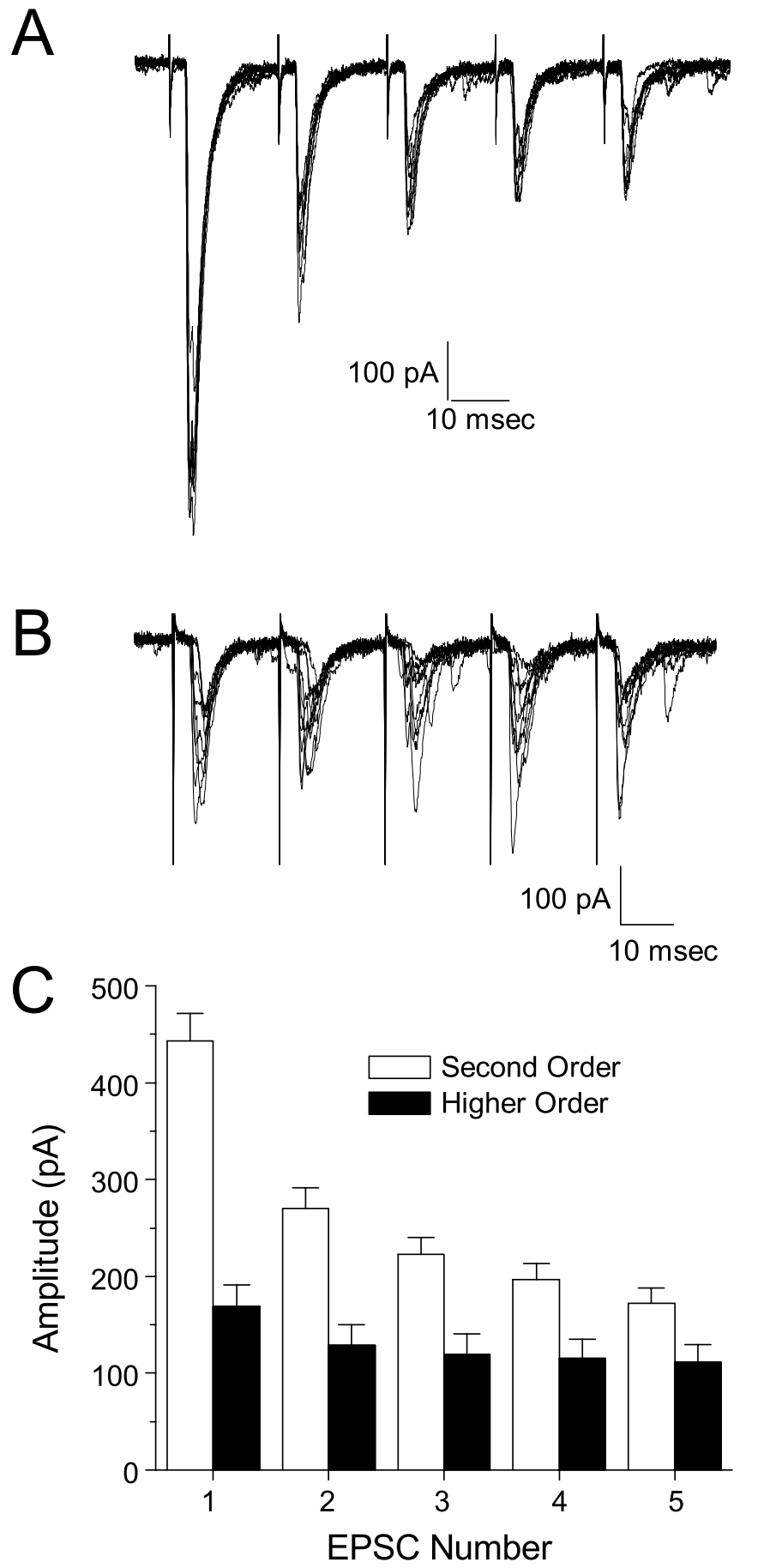

Figure 5. FDD of monosynaptic and polysynaptic ST inputs to NTS CA neurons. Bursts of five ST shocks evoked a series of EPSC $s$ in these neurons. $A, A$ representative NTS CA neuron with a single monosynaptic EPSC (latency, 3.0; jitter, $117 \mu \mathrm{s}$ ) shows that, in 10 consecutive traces, bursts of five ST-shocks ( $50 \mathrm{~Hz}$ ) evoked progressively smaller EPSCS as the burst progressed. Note that the synaptic responses fully recovered over the 3 s interval between bursts of shocks. Similar, substantial FDD was found in all monosynaptic ST-EPSCs in NTS CA neurons. $\boldsymbol{B}$, A representative NTS CA neuron with polysynaptic EPSCs (latency, 4.0; jitter, $336 \mu$ s) shows that, in 10 consecutive traces, bursts of five ST-shocks (50 Hz) evoked constant-amplitude EPSCs throughout the burst. C, Summary averages for amplitudes of EPSC1, 2, 3, 4, and 5 from neurons receiving either direct (i.e., second order) $(n=64)$ or only indirect ST inputs (i.e., higher order) $(n=7)$. Neurons receiving only indirect inputs have significantly smaller EPSC amplitudes (EPSC1-4) than neurons receiving direct inputs $(p<0.01)$. FDD significantly depressed the mean amplitude of ST-EPSCs during the train of five in neurons receiving only direct inputs $(p<0.01)$. FDD was significantly greater in neurons receiving direct inputs than neurons receiving only indirect inputs $(p<0.01)$. Error bars indicate SEM.
NTS CA neurons express a large transient outward current Translation of synaptic inputs into propagated spikes depends on spike generation and the ion channels mediating that process, and this process is particularly sensitive to the presence of particular potassium channels (Lai and Jan, 2006). Depolarization of NTS CA neurons evoked a substantial early transient outward current $\left(I_{\mathrm{KA}}\right)$ that decayed over several hundred milliseconds to a sustained current $\left(I_{\mathrm{KV}}\right)$ (Fig. $\left.6 A\right)$. Application of 4AP $(n=5)$ completely blocked $I_{\mathrm{KA}}$, leaving only the steady $I_{\mathrm{KV}}$ (Fig. $6 \mathrm{~B}$ ). The $4 \mathrm{AP}$-sensitive current was evoked in a test step to $0 \mathrm{mV}$ and completely inactivated within $250 \mathrm{~ms}$. $I_{\mathrm{KA}}$ activated at membrane potentials beginning at $-50 \mathrm{mV}$. Inactivation of $I_{\mathrm{KA}}$ was also steeply dependent on voltage particularly in the range around the resting potential of these neurons, from -80 to $-60 \mathrm{mV}$ (Fig. $6 C)(n=38)$. The time- and voltage-dependent properties of this transient outward current and its pharmacology, closely resemble the $I_{\mathrm{KA}}$ in rat NTS neurons (Bailey et al., 2002). The amplitudes of both $I_{\mathrm{KA}}$ and $I_{\mathrm{KV}}$ varied widely among NTS CA neurons (Fig. 6D) so that potassium channel expression appears to be a source of heterogeneity across NTS CA neurons. Because we did not standardize to cell size, this could be one source of the variability; however, it is unlikely to account for such a wide range of current amplitudes.

\section{Discharge properties of NTS CA neurons}

The resting membrane potentials of NTS CA neurons ranged from -86 to $-59 \mathrm{mV}(69 \pm 1.1 \mathrm{mV} ; n=36)$ and, therefore, centered on the voltage window for $I_{\mathrm{KA}}$. Most NTS CA neurons spontaneously discharged APs at their resting membrane potential (28 of 37) at an average rate of $6 \pm 0.73 \mathrm{~Hz}(n=28)$. Because $I_{\mathrm{KA}}$ strongly modulates firing rate, action potential threshold, and interspike interval (Dekin and Getting, 1987; Schild et al., 1993; Pongs, 1999), we assessed the potential impact of $I_{\mathrm{KA}}$ on spike encoding in NTS CA neurons. At resting potential, neurons that expressed a large $I_{\mathrm{KA}}$ responded to depolarizing current injections with sustained volleys of action potentials as did neurons that expressed a small $I_{\mathrm{KA}}$ (Fig. 7A1,B1). However, briefly conditioning neurons with a hyperpolarizing current injection to remove inactivation of $I_{\mathrm{KA}}$ produced a substantial delay in the onset of AP firing on depolarizing current injection only in neurons that expressed a large $I_{\mathrm{KA}}$ (Fig. 7A2,B2). This delay lasted $\sim 250$ $\mathrm{ms}$ and corresponds with the time necessary for $I_{\mathrm{KA}}$ to inactivate (Fig. 7A2).

\section{$I_{\mathrm{KA}}$ decreases the fidelity of ST-evoked action potential generation}

ST shocks successfully evoked similar numbers of APs in neurons that expressed either a large or small $I_{\mathrm{KA}}$ (Fig. 8). However, conditioning neurons at hyperpolarized potentials significantly reduced the number of ST-evoked APs evoked in neurons expressing a large $I_{\mathrm{KA}}$ (Fig. $8 \mathrm{~A}$ ). Expressing such responses as a success ratio (spikes/shocks or I:O), we computed an early I:O for the first two shocks given in the burst of five and a late I:O for responses to shocks 4 and 5 . In our conditioning paradigm, the early I:O response occurred within $250 \mathrm{~ms}$, before $I_{\mathrm{KA}}$ inactivates, and the late I:O responses occurred at a time when $I_{\mathrm{KA}}$ was inactivated. In NTS CA neurons expressing a large $I_{\mathrm{KA}}$ at resting membrane potential, the early I:O averaged $0.91 \pm 0.04$ and the late I:O averaged $0.91 \pm 0.04$ (trials, 72 ; from four neurons). Removing $I_{\mathrm{KA}}$ inactivation by a hyperpolarizing conditioning step in the same neurons reduced the early I:O to $0.37 \pm 0.06$ but the late I:O remained $0.89 \pm 0.04$ (trials, 76 ; from the same 4 neurons). In NTS CA neurons with little $I_{\mathrm{KA}}$, the early and late I:O 

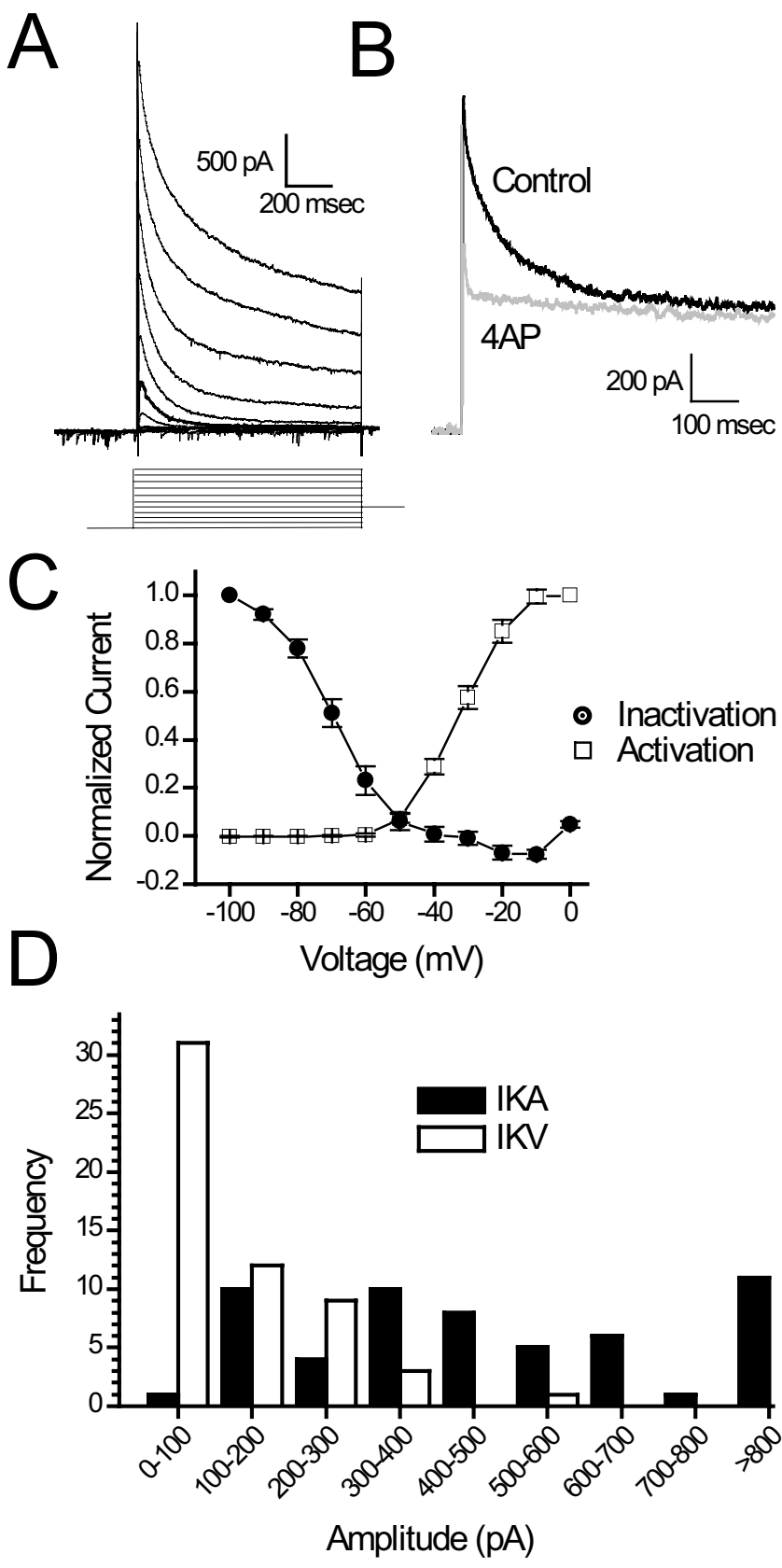

Figure 6. Most NTS CA neurons express substantial, early transient outward current $\left(/_{\mathrm{KA}}\right) \cdot A$, In a representative NTS CA neuron expressing a large $I_{\mathrm{KA}}$, depolarizing steps evoked currents with a large, early component that rapidly decayed to steadier levels within $200 \mathrm{~ms}$. Under voltage clamp, neurons were preconditioned at $-100 \mathrm{mV}$ before stepping to test levels starting at $-100 \mathrm{mV}$ and increasing by $+10 \mathrm{mV}$ with each sweep. $\boldsymbol{B}, 4 \mathrm{AP}$ blocked the early, transient current, consistent with $I_{\text {KA }}$. Currents were evoked by a test step to $0 \mathrm{mV}$ after a conditioning step to $-100 \mathrm{mV}$ without (control) and with $5 \mathrm{~mm}$ 4AP. C, Plots of mean activation and inactivation curves for $I_{\text {KA }}$ (peak current minus persistent current) indicate a critical voltage dependence near resting potentials for these neurons $(n=61)$. Error bars indicate SEM. $D$, Histogram showing the distributions of the $I_{\mathrm{KA}}$ and $I_{\mathrm{KV}}$ current amplitudes for second order neurons at $-30 \mathrm{mV}$.

values were similar $(1.06 \pm 0.04$ vs $1.02 \pm 0.03$; trials, 52 ; from three neurons) at resting potentials and were not decreased by hyperpolarizing preconditioning $(1.23 \pm 0.05$ vs $1.06 \pm 0.03$; trials, 66; from the same three neurons).
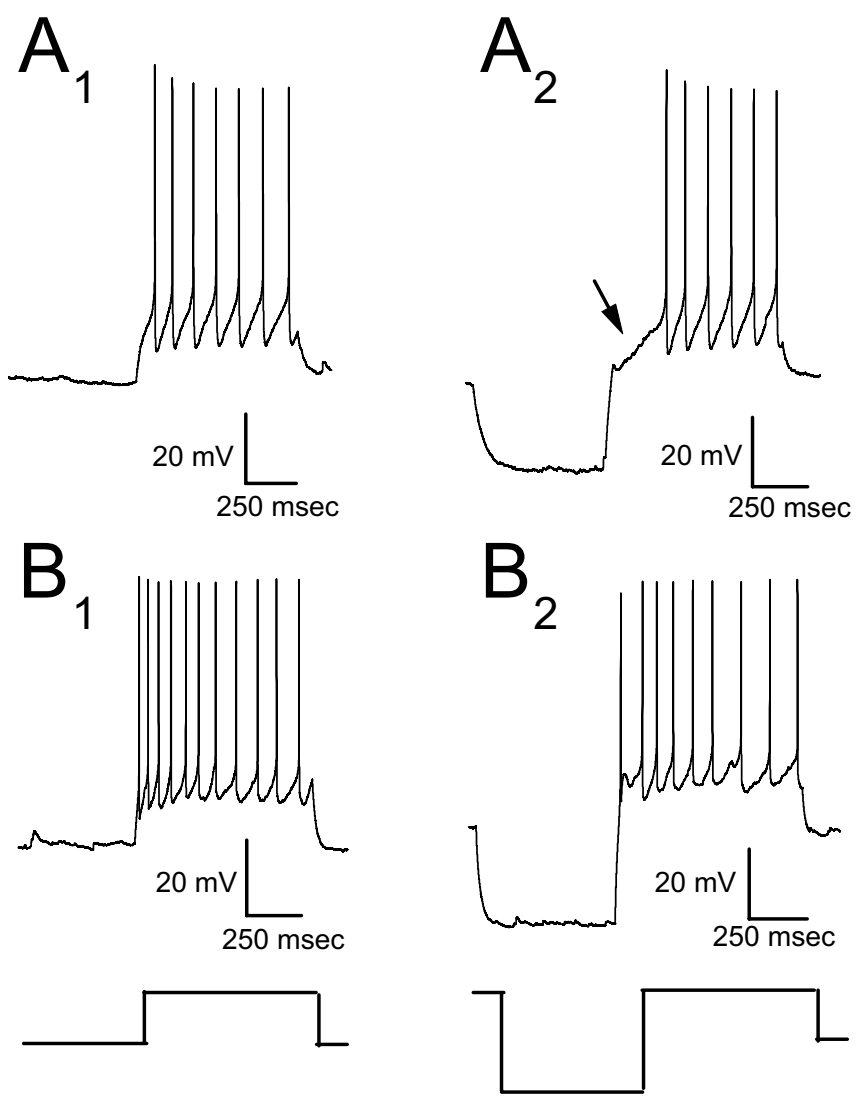

Figure 7. $I_{\mathrm{KA}}$ greatly affects the discharge rate of NTS CA neurons. $A$, In an NTS CA neuron that expressed a large $I_{\mathrm{KA}}$ (data not shown), injection of constant depolarizing current $(+20 \mathrm{pA})$ at resting potential $(-73 \mathrm{mV})$ evoked a high rate of discharge $\left(A_{7}\right)$. In the same neuron after a preconditioning hyperpolarization to $-90 \mathrm{mV}$ for $500 \mathrm{~ms}(-20 \mathrm{pA})$, the same constant depolarizing current $(+20 \mathrm{pA})$ triggered discharge only after a long delay $\left(\boldsymbol{A}_{2}\right.$; arrow indicates delay). $\boldsymbol{B}$, Conversely, in an NTS CA neuron that expressed a little $I_{K A}$ (data not shown), injection of constant depolarizing current $(+45 \mathrm{pA})$ at resting potential $(-70 \mathrm{mV})$ evoked similar rates of discharge whether from resting potential $\left(\boldsymbol{B}_{1}\right)$ or after hyperpolarization $(-75 \mathrm{pA})$ to -90 $\mathrm{mV}\left(\boldsymbol{B}_{2}\right)$. Timing and directions of current injection steps in these current-clamp recordings are indicated diagrammatically in the lowest traces.

\section{CCK sensitivity of NTS CA neurons}

Because CCK activates gene transcription in many NTS CA neurons in vivo (Monnikes et al., 1997; Willing and Berthoud, 1997; Rinaman et al., 1998), we tested whether TH-EGFP neurons were CCK-sensitive. To isolate EPSCs, we recorded mEPSCs in the presence of the $\mathrm{GABA}_{\mathrm{A}}$ receptor blocker gabazine and TTX. The rate of mEPSCs was highly variable between TH-EGFP neurons ranging from 0.13 to $6.4 \mathrm{~Hz}$. CCK (100 nM) rapidly increased the frequency of mEPSCs in five of eight of the NTS CA neurons tested an average of $3.4 \pm 1.0$-fold, an effect that was reversed by wash (Fig. 9A). CCK-insensitive NTS CA neurons showed no increase in frequency (Fig. 9B). The control mEPSC frequency was not statistically different between CCK-sensitive ( $2.1 \pm 1.2$ $\mathrm{Hz})$ and CCK-insensitive $(2.3 \pm 1.1 \mathrm{~Hz})$ neurons. CCK did not consistently alter the amplitude of the mEPSCs, suggesting that the CCK site of action was presynaptic.

\section{Discussion}

Visceral afferents directly activate NTS CA neurons

Despite the diverse roles attributed to NTS CA neurons, our studies identified several key attributes of these neurons that were remarkably homogeneous. Ninety percent of NTS CA neurons received direct inputs from the glutamatergic terminals of cranial 


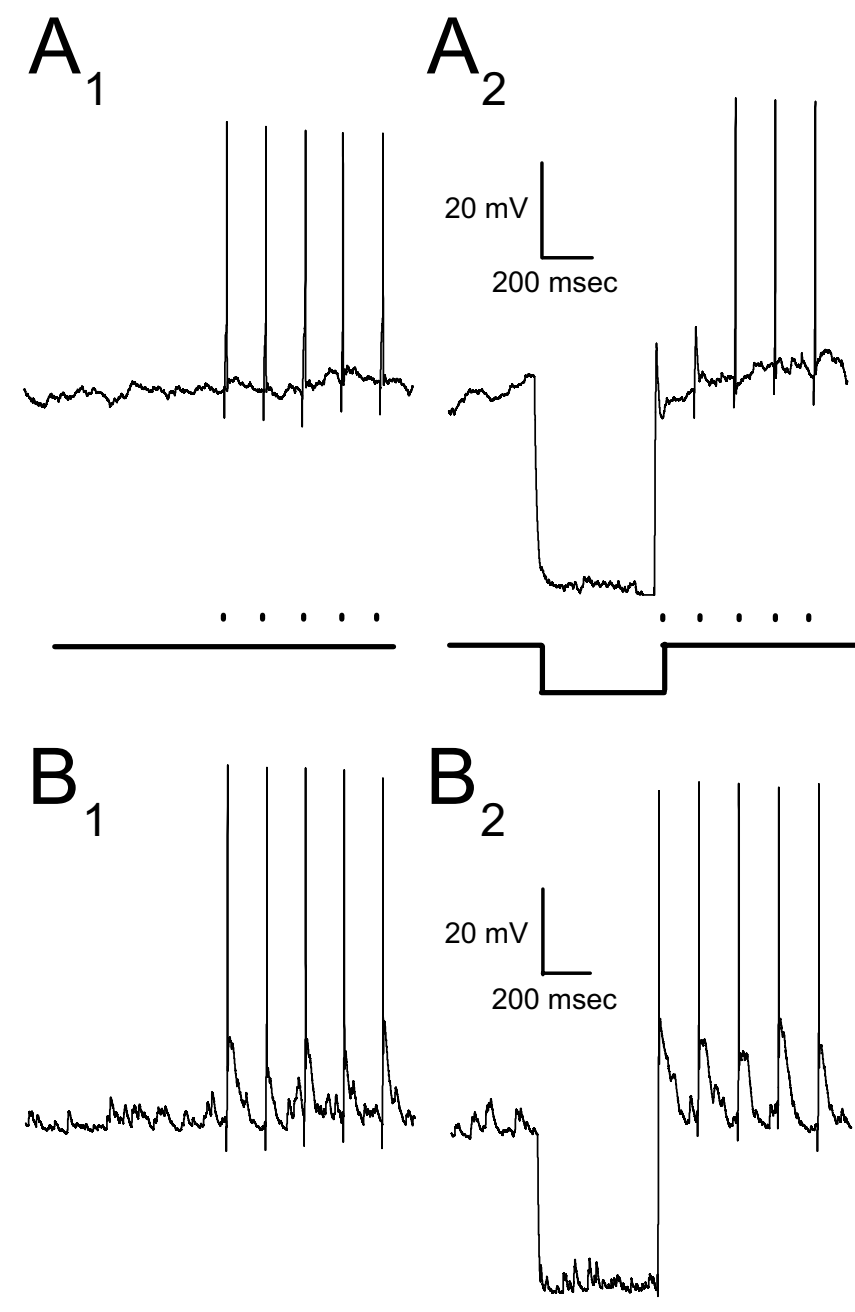

Figure 8. Presence of $I_{K A}$ in NTS CA neurons reduces APs generated by $S T$-activation. $A$, In a representative NTS CA neuron expressing a large $I_{K A}$ (data not shown) (resting potential, -69 $\mathrm{mV}$ ), shocks to ST ( $5 \mathrm{~Hz}$ ) always evoked an action potential (left, $A_{7} ; 5$ of 5 successes), but, after hyperpolarization $(-200 \mathrm{pA})$ to $-100 \mathrm{mV}$, ST-evoked action potentials were reduced (right, $A_{2} ; 3$ of 5 successes). $\boldsymbol{B}$, In an NTS (A neuron that expressed a little $I_{\text {KA }}$ (data not shown), a similar hyperpolarization preconditioning step to $-100 \mathrm{mV}(-250 \mathrm{pA})$ had no effect on ST-evoked action potential successes (right, $\boldsymbol{B}_{1}$, and left, $\boldsymbol{B}_{2}$, respectively). Timing and directions of current injection steps in these current-clamp recordings are indicated diagrammatically in the middle traces in which dots indicate shocks to ST.

visceral primary afferent fibers. These ST afferent synapses produced tightly synced, large-amplitude EPSCs and thus provided a high fidelity of transmission of afferent activity. Interestingly, the afferent information appears to converge on NTS CA neurons by both direct and indirect pathways. Directly activated ST-EPSCs strongly depressed at moderate afferent frequencies $(50 \mathrm{~Hz})$. Furthermore, a combination of presynaptic and postsynaptic characteristics tunes the dynamic responsiveness of ST afferent excitatory transmission to NTS CA neurons.

\section{Visceral integration and NTS CA neurons}

The location of CA neurons amid the terminal fields of visceral afferents led to a general assumption that NTS CA neurons broadly integrate afferent information and relay it to multiple brain regions via their extensive projections (Chiba and Kato, 1978; Takahashi et al., 1979; Kalia et al., 1985a,b; Mtui et al., 1995). Activation of afferents from gastrointestinal, cardiovascular, and respiratory targets supported widespread stimulation of
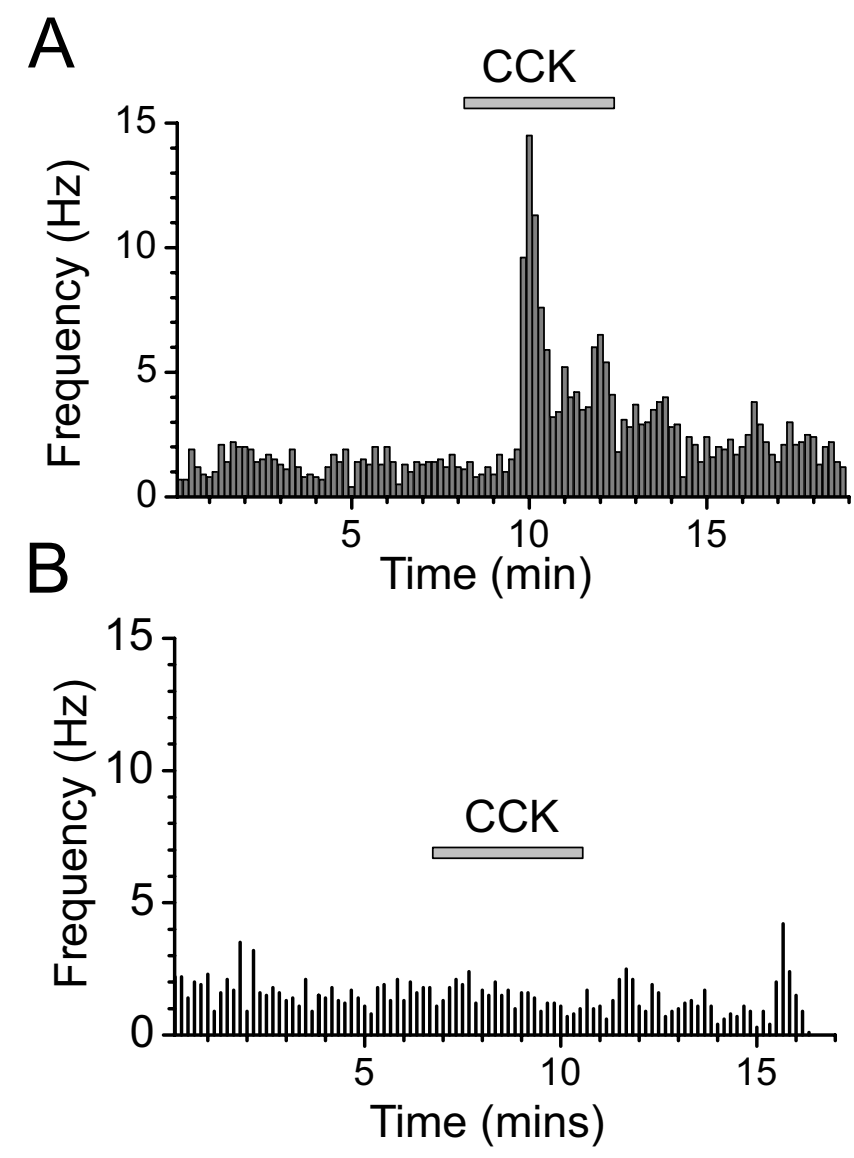

Figure 9. CCK presynaptically increases glutamate release in one-half of NTS CA neurons. In second-order NTS CA neurons (data not shown), mEPSCs were isolated pharmacologically using $1 \mu \mathrm{M}$ TTX and $2 \mu \mathrm{m}$ gabazine. CCK (100 nM) increased the rate of mEPSCs in some neurons (neuron $A$ ) but not in others (neuron $B$ ), and this effect was reversed by a 10 min wash. In CCK-sensitive neurons, CCK increased the frequency of mEPSCs during a 5 min exposure ( $K-S$ test, $p<0.05$ ) but did not consistently alter amplitudes (data not shown). Together, these findings suggest that CCK acts presynaptically to increase glutamate release in sensitive neurons. Each bar represents the number of events in a 10 s time period.

CA NTS neurons in various behaviors including sleep and stress (Murphy et al., 1994; Chan and Sawchenko, 1998; Dayas et al., 2004; Kubin et al., 2006). Furthermore, changes in blood pressure (Chan and Sawchenko, 1998), opioid withdrawal (Laorden et al., 2002), noxious stimuli (Jin et al., 1994), and immune challenge (Lacroix and Rivest, 1997) activate c-fos expression in subpopulations of NTS CA neurons. Thus, visceral afferent regulation of the NTS CA neurons is broadly implicated in homeostatic control and the NTS CA cell groups likely provide the critical link with other brain regions that produce the behavioral outcomes.

\section{Afferent pathways to NTS CA neurons}

A major objective of this study was to define the nature of the functional connections between ST afferents and NTS CA neurons. Neuroanatomical approaches demonstrate that vagal sensory afferents terminate in close appositions on NTS CA neurons (Sumal et al., 1983), but such studies cannot assess the functional impact or afferent convergence from the source axons. Shock intensity-recruitment responses for NTS CA neurons showed individual CA neurons do not broadly integrate from a large number of different afferent inputs. In many cases, one NTS CA neuron appears to receive an input from only one afferent fiber, a common pattern found in medial NTS in the rat (Doyle and 
Andresen, 2001; Bailey et al., 2006b) and guinea pig (Miles, 1986). The implication is that NTS CA neurons commonly receive modality-specific afferent information. However, over onehalf of NTS CA neurons in our studies, received two monosynaptic ST inputs that were independently recruited with electrical shocks of different intensities. Convergent ST inputs could represent either congruent modalities (e.g., two mechanoreceptors from the heart) or afferents of different origins (e.g., a chemoreceptor and a mechanoreceptor from the stomach). There is evidence for some level of convergence from discrete visceral sources from in vivo extracellular recordings (Donoghue et al., 1985; Chambert et al., 1993; Mifflin, 1996; Silva-Carvalho et al., 1998; Zhang et al., 1998). However, such recordings of extracellular spike activity may lack sufficient timing precision to discriminate direct inputs from indirect, polysynaptic intra-NTS pathways. Here, we found convergence at two levels. First, over one-half of the NTS CA neurons receive dual direct inputs, and second, many of the neurons that only received one direct input received additional indirect afferent driven inputs that increase the complexity of afferent processing and convergence of afferent information. In these cases, neurons would respond in synaptically weighted manner with a strong direct afferent input followed by secondary, weaker influences via polysynaptic inputs. The possibility of cross-organ convergence is intriguing because it could mediate potential cross talk between reflex pathways (e.g., satiety signals influencing cardiac function).

\section{Frequency-dependent processing in NTS CA neurons}

Neuronal processing is frequently altered by both short- and long-term forms of synaptic plasticity. FDD often shapes afferent transmission with a form of short-term synaptic plasticity (Trussell, 1999; Zucker and Regehr, 2002) that in part arises from the high quantal release properties of excitatory synapses such as the afferent synapses found in the NTS (von Gersdorff and Borst, 2002; Bailey et al., 2006a). This form of plasticity would be expected to give transmission through these synapses substantial dynamic features. Specifically, the response of NTS CA neurons to sensory afferent discharge at high frequencies (up to $100 \mathrm{~Hz}$ ) will be substantially depressed, whereas their response to lowfrequency discharge $(<1 \mathrm{~Hz})$ will be unaffected. This frequencydependent depression will occur well within the range (1-100 $\mathrm{Hz}$ ) of cranial visceral afferents (Coleridge and Coleridge, 1984; Andresen and Kunze, 1994; Moran et al., 2001). Interestingly, FDD was not observed with indirect inputs. Thus, on the basis of synaptic properties alone, direct and indirect inputs may have different synaptic weighting that changes depending on the frequency and duration of an afferent activation.

\section{Translation of synaptic excitation into action potential output}

ST afferent shocks activated NTS CA neurons quite reliably at modest firing rates $(5 \mathrm{~Hz})$. However, expression of a substantial $I_{\mathrm{KA}}$ in many CA neurons shaped output by greatly attenuating the number of action potentials evoked early, but not late, in an afferent burst. $I_{\mathrm{KA}}$, although common, is not universally expressed in NTS neurons (Dekin and Getting, 1987; Bailey et al., 2002; Baptista et al., 2005a). Thus, $I_{\mathrm{KA}}$ and its influence on neuronal excitability is a clear source of heterogeneity across NTS CA neurons. Interestingly, NTS neurons that project to the paraventricular nucleus (PVN) express a much larger $I_{\mathrm{KA}}$ than neurons that project to the CVLM (caudal ventrolateral medulla) (Bailey et al., 2007) as do NTS neurons that are sensitive to capsaicin (Bailey et al., 2002). Thus, $I_{\mathrm{KA}}$ expression in NTS CA neurons might be linked to other pathway characteristics. The finding that many PVN-projecting neurons express a large $I_{\mathrm{KA}}$ is particularly interesting given that CA neurons form a major neural pathway relaying visceral sensory afferent information from the brainstem to the PVN (Sawchenko and Swanson, 1982). The inactivation and activation plots for $I_{\mathrm{KA}}$ in NTS CA neurons suggest that the size of this current will critically change during even small shifts in resting membrane potential. The extensive GABA inputs (Jia et al., 1997) on NTS CA neurons as well as various neurotransmitters that are expressed in the NTS, including opioids (Zhu and Pan, 2005), could substantially alter $I_{\mathrm{KA}}$ and thus translation of synaptic excitation into projected AP output.

\section{CCK regulation of NTS CA neurons}

CCK has diverse effects on homeostatic functions, including the modulation of mood, stress, and cardiovascular function; however, it is particularly prominent in feeding behavior (Verberne et al., 2003; Dayas et al., 2004). We found NTS CA neurons are heterogenous in their response to CCK, similar to TH-IR rat centralis neurons (Baptista et al., 2005b). In contrast, all NTS neurons that express POMC were CCK-sensitive (Appleyard et al., 2005). This difference probably reflects the diverse functional roles proposed for NTS CA neurons compared with NTS POMC neurons. The effects of CCK appeared presynaptic. CCK increases glutamate release from both afferent (Appleyard et al., 2005) and nonafferent terminals (Baptista et al., 2007) and it remains to be determined whether its effects on CA neurons are through regulation of afferent terminals, local NTS neurons, or projection neurons. NTS CA neurons are essential for CCK inhibition of food intake (Rinaman, 2003) and CCK-responsive neurons probably contribute to pathways that inhibit food intake. However, CCK regulates other functions and information about energy balance is conveyed by CCK-insensitive afferents (Ritter, 2004). Thus, CCK is not solely linked to feeding mechanisms. Potential neural sources of CCK within NTS include fibers from both local and distant CCK neurons (Takagi et al., 1984) as well as the afferents themselves (Broberger et al., 2001).

\section{Physiological implications for NTS CA neurons in homeostatic regulation}

Despite the functional diversity of CA neurons in the NTS, we found surprisingly homogeneous synaptic organization of these neurons. Therefore, specificity in the distribution of afferent innervation may well contribute to these diverse roles and create subpopulations of NTS CA neurons. For example, NTS CA neurons appear to be essential for both the inhibition and stimulation of food intake (Ritter et al., 2001; Rogers et al., 2003; Patil and Briski, 2005; Date et al., 2006). Subpopulations of NTS CA neurons could be activated by GI afferents that inhibit food intake, whereas other sensory afferents, including hepatic, esophageal, and some vagal afferents could activate distinct pathways that stimulate food intake (Niijima, 1983; Ritter et al., 1994; Berthoud, 2004). However, clearly where a given CA neuron projects and the types of CA receptors expressed at that distal site will also determine whether that neuron mediates a stimulatory or inhibitory effect on food intake (Wellman, 2005).

In summary, our data show NTS CA neurons receive direct glutamatergic inputs from one or two individual visceral afferent fibers, resulting in large-amplitude EPSCs that almost always elicit action potentials. Peptidergic modulation of glutamate release and postsynaptic ionic conductances both contribute to regulate afferent transmission along these critical CA reflex pathways. 


\section{References}

Andresen MC, Kunze DL (1994) Nucleus tractus solitarius-gateway to neural circulatory control. Annu Rev Physiol 56:93-116.

Andresen MC, Yang M (1995) Dynamics of sensory afferent synaptic transmission in aortic baroreceptor regions of nucleus trachus solitarius. J Neurophysiol 74:1518-1528.

Appleyard SM, Bailey TW, Doyle MW, Jin YH, Smart JL, Low MJ, Andresen MC (2005) Proopiomelanocortin neurons in nucleus tractus solitarius are activated by visceral afferents: regulation by cholecystokinin and opioids. J Neurosci 25:3578-3585.

Bailey TW, Jin YH, Doyle MW, Andresen MC (2002) Vanilloid-sensitive afferents activate neurons with prominent A-type potassium currents in nucleus tractus solitarius. J Neurosci 22:8230-8237.

Bailey TW, Jin YH, Doyle MW, Smith SM, Andresen MC (2006a) Vasopressin inhibits glutamate release via two distinct modes in the brainstem. J Neurosci 26:6131-6142.

Bailey TW, Hermes SM, Andresen MC, Aicher SA (2006b) Cranial visceral afferent pathways through the nucleus of the solitary tract to caudal ventrolateral medulla or paraventricular hypothalamus: target-specific synaptic reliability and convergence patterns. J Neurosci 26:11893-11902.

Bailey TW, Hermes SM, Whittier KL, Aicher SA, Andresen MC (2007) A-type potassium channels differentially tune afferent pathways from rat solitary tract nucleus to caudal ventrolateral medulla or paraventricular hypothalamus. J Physiol (Lond) 582:613-628.

Baptista V, Zheng ZL, Coleman FH, Rogers RC, Travagli RA (2005a) Characterization of neurons of the nucleus tractus solitarius pars centralis. Brain Res 1052:139-146.

Baptista V, Zheng ZL, Coleman FH, Rogers RC, Travagli RA (2005b) Cholecystokinin octapeptide increases spontaneous glutamatergic synaptic transmission to neurons of the nucleus tractus solitarius centralis. J Neurophysiol 94:2763-2771.

Baptista V, Browning KN, Travagli RA (2007) Effects of cholecystokinin-8s in the nucleus tractus solitarius of vagally deafferented rats. Am J Physiol 292:R1092-R1100.

Berthoud HR (2004) Anatomy and function of sensory hepatic nerves. Anat Rec A Discov Mol Cell Evol Biol 280:827-835.

Broberger C, Holmberg K, Shi TJ, Dockray G, Hokfelt T (2001) Expression and regulation of cholecystokinin and cholecystokinin receptors in rat nodose and dorsal root ganglia. Brain Res 903:128-140.

Buller KM, Day TA (1996) Involvement of medullary catecholamine cells in neuroendocrine responses to systemic cholecystokinin. J Neuroendocrinol 8:819-824.

Buzsaki G, Chrobak JJ (1995) Temporal structure in spatially organized neuronal ensembles: a role for interneuronal networks. Curr Opin Neurobiol 5:504-510.

Chambert G, Kobashi M, Adachi A (1993) Convergence of gastric and hepatic information in brain stem neurons of the rat. Brain Res Bull 32:525-529.

Chan RK, Sawchenko PE (1998) Organization and transmitter specificity of medullary neurons activated by sustained hypertension: implications for understanding baroreceptor reflex circuitry. J Neurosci 18:371-387.

Chiba T, Kato M (1978) Synaptic structures and quantification of catecholaminergic axons in the nucleus tractus solitarius of the rat: possible modulatory roles of catecholamines in baroreceptor reflexes. Brain Res 151:323-338.

Coleridge JC, Coleridge HM (1984) Afferent vagal C fibre innervation of the lungs and airways and its functional significance. Rev Physiol Biochem Pharmacol 99:1-110.

Dahlstrom A, Fuxe K (1964) Localization of monoamines in the lower brain stem. Experientia 20:398-399.

Date Y, Shimbara T, Koda S, Toshinai K, Ida T, Murakami N, Miyazato M, Kokame K, Ishizuka Y, Ishida Y, Kageyama H, Shioda S, Kangawa K, Nakazato M (2006) Peripheral ghrelin transmits orexigenic signals through the noradrenergic pathway from the hindbrain to the hypothalamus. Cell Metab 4:323-331.

Dayas CV, Buller KM, Day TA (2004) Hypothalamic paraventricular nucleus neurons regulate medullary catecholamine cell responses to restraint stress. J Comp Neurol 478:22-34.

Dekin MS, Getting PA (1987) In vitro characterization of neurons in the ventral part of the nucleus tractus solitarius. II. Ionic basis for repetitive firing patterns. J Neurophysiol 58:215-229.

Donoghue S, Felder RB, Gilbey MP, Jordan D, Spyer KM (1985) Post- synaptic activity evoked in the nucleus tractus solitarius by carotid sinus and aortic nerve afferents in the cat. J Physiol (Lond) 360:261-273.

Doyle MW, Andresen MC (2001) Reliability of monosynaptic sensory transmission in brain stem neurons in vitro. J Neurophysiol 85:2213-2223.

Hollis JH, Lightman SL, Lowry CA (2004) Integration of systemic and visceral sensory information by medullary catecholaminergic systems during peripheral inflammation. Ann NY Acad Sci 1018:71-75.

Jia HG, Rao ZR, Shi JW (1997) Evidence of gamma-aminobutyric acidergic control over the catecholaminergic projection from the medulla oblongata to the central nucleus of the amygdada. J Comp Neurol 381:262-281.

Jin GR, Rao ZR, Shi JW (1994) Visceral noxious stimulation induced expression of Fos protein in medullary catecholaminergic neurons projecting to nucleus accumbens in the rat: a study with triple labeling method of HRP tracing combined with Fos and TH immunohistochemistry. Brain Res 648:196-202.

Kalia M, Fuxe K, Goldstein M (1985a) Rat medulla oblongata. II. Dopaminergic, noradrenergic (A1 and A2) and adrenergic neurons, nerve fibers, and presumptive terminal processes. J Comp Neurol 233:308-332.

Kalia M, Fuxe K, Goldstein M (1985b) Rat medulla oblongata. III. Adrenergic ( $\mathrm{C} 1$ and $\mathrm{C} 2$ ) neurons, nerve fibers and presumptive terminal processes. J Comp Neurol 233:333-349.

Kubin L, Alheid GF, Zuperku EJ, McCrimmon DR (2006) Central pathways of pulmonary and lower airway vagal afferents. J Appl Physiol 101:618-627.

Lacroix S, Rivest S (1997) Functional circuitry in the brain of immunechallenged rats: partial involvement of prostaglandins. J Comp Neurol 387:307-324.

Lai HC, Jan LY (2006) The distribution and targeting of neuronal voltagegated ion channels. Nat Rev Neurosci 7:548-562.

Laorden ML, Castells MT, Milanes MV (2002) Effects of morphine and morphine withdrawal on brainstem neurons innervating hypothalamic nuclei that control the pituitary-adrenocortical axis in rats. Br J Pharmacol 136:67-75.

Matsushita N, Okada H, Yasoshima Y, Takahashi K, Kiuchi K, Kobayashi K (2002) Dynamics of tyrosine hydroxylase promoter activity during midbrain dopaminergic neuron development. J Neurochem 82:295-304.

Mifflin SW (1996) Convergent carotid sinus nerve and superior laryngeal nerve afferent inputs to neurons in the NTS. Am J Physiol 271:R870-R880.

Miles R (1986) Frequency dependence of synaptic transmission in nucleus of the solitary tract in vitro. J Neurophysiol 55:1076-1090.

Moak JP, Kunze DL (1993) Potassium currents of neurons isolated from medical nucleus tractus solitarius. Am J Physiol 265:H1596-H1602.

Monnikes H, Lauer G, Arnold R (1997) Peripheral administration of cholecystokinin activates c-fos expression in the locus coeruleus/subcoeruleus nucleus, dorsal vagal complex and paraventricular nucleus via capsaicinsensitive vagal afferents and CCK-A receptors in the rat. Brain Res 770:277-288.

Moran TH, Ladenheim EE, Schwartz GJ (2001) Within-meal gut feedback signaling. Int J Obes Relat Metab Disord 25 [Suppl 5]:S39-S41.

Mtui EP, Anwar M, Reis DJ, Ruggiero DA (1995) Medullary visceral reflex circuits: local afferents to nucleus tractus solitarii synthesize catecholamines and project to thoracic spinal cord. J Comp Neurol 351:5-26.

Murphy AZ, Ennis M, Shipley MT, Behbehani MM (1994) Directionally specific changes in arterial pressure induce differential patterns of fos expression in discrete areas of the rat brainstem: a double-labeling study for Fos and catecholamines. J Comp Neurol 349:36-50.

Niijima A (1983) Glucose-sensitive afferent nerve fibers in the liver and their role in food intake and blood glucose regulation. J Auton Nerv Syst 9:207-220.

Onaka T (2000) Catecholaminergic mechanisms underlying neurohypophysial hormone responses to unconditioned or conditioned aversive stimuli in rats. Exp Physiol 85:101S-110S.

Patil GD, Briski KP (2005) Lactate is a critical "sensed" variable in caudal hindbrain monitoring of CNS metabolic stasis. Am J Physiol 289:R1777-R1786.

Paxinos F (2001) The mouse brain in stereotaxic coordinates, Ed 2. San Diego: Academic.

Petrov T, Krukoff TL, Jhamandas JH (1993) Branching projections of catecholaminergic brainstem neurons to the paraventricular hypothalamic 
nucleus and the central nucleus of the amygdala in the rat. Brain Res 609:81-92.

Pongs O (1999) Voltage-gated potassium channels: from hyperexcitability to excitement. FEBS Lett 452:31-35.

Riche D, De Pommery J, Menetrey D (1990) Neuropeptides and catecholamines in efferent projections of the nuclei of the solitary tract in the rat. J Comp Neurol 293:399-424.

Rinaman L (2003) Hindbrain noradrenergic lesions attenuate anorexia and alter central c-Fos expression in rats after gastric viscerosensory stimulation. J Neurosci 23:10084-10092.

Rinaman L, Baker EA, Hoffman GE, Stricker EM, Verbalis JG (1998) Medullary c-Fos activation in rats after ingestion of a satiating meal. Am J Physiol 275:R262-R268.

Ritter RC (2004) Increased food intake and CCK receptor antagonists: beyond abdominal vagal afferents. Am J Physiol 286:R991-R993.

Ritter S, Dinh TT, Friedman MI (1994) Induction of Fos-like immunoreactivity (Fos-li) and stimulation of feeding by 2,5-anhydro-D-mannitol (2,5-AM) require the vagus nerve. Brain Res 646:53-64.

Ritter S, Bugarith K, Dinh TT (2001) Immunotoxic destruction of distinct catecholamine subgroups produces selective impairment of glucoregulatory responses and neuronal activation. J Comp Neurol 432:197-216.

Rogers RC, Travagli RA, Hermann GE (2003) Noradrenergic neurons in the rat solitary nucleus participate in the esophageal-gastric relaxation reflex. Am J Physiol 285:R479-R489.

Saper CB (2002) The central autonomic nervous system: conscious visceral perception and autonomic pattern generation. Annu Rev Neurosci 25:433-469.

Sawamoto K, Nakao N, Kobayashi K, Matsushita N, Takahashi H, Kakishita $\mathrm{K}$, Yamamoto A, Yoshizaki T, Terashima T, Murakami F, Itakura T, Okano H (2001) Visualization, direct isolation, and transplantation of midbrain dopaminergic neurons. Proc Natl Acad Sci USA 98:6423-6428.

Sawchenko PE, Swanson LW (1982) The organization of noradrenergic pathways from the brainstem to the paraventricular and supraoptic nuclei in the rat. Brain Res 257:275-325.

Schild JH, Khushalani S, Clark JW, Andresen MC, Kunze DL, Yang M (1993) An ionic current model for neurons in the rat medial nucleus tractus solitarii receiving sensory afferent input. J Physiol (Lond) 469:341-363.

Silva-Carvalho L, Paton JF, Rocha I, Goldsmith GE, Spyer KM (1998) Convergence properties of solitary tract neurons responsive to cardiac receptor stimulation in the anesthetized cat. J Neurophysiol 79:2374-2382.

Sumal KK, Blessing WW, Joh TH, Reis DJ, Pickel VM (1983) Synaptic interaction of vagal afferents and catecholaminergic neurons in the rat nucleus tractus solitarius. Brain Res 277:31-40.
Takagi H, Mizuta H, Matsuda T, Inagaki S, Tateishi K, Hamaoka T (1984) The occurrence of cholecystokinin-like immunoreactive neurons in the rat neostriatum: light and electron microscopic analysis. Brain Res 309:346-349.

Takahashi Y, Satoh K, Sakumoto T, Tohyama M, Shimizu N (1979) A major source of catecholamine terminals in the nucleus tractus solitaril. Brain Res 172:372-377.

Talman WT, Andreasen K, Calvin J, Eversmann-Johanns S (1991) Cholecystokinin in nucleus tractus solitarii modulates tonic and phasic gastric pressure. Am J Physiol 261:R217-R222.

Travagli RA, Hermann GE, Browning KN, Rogers RC (2006) Brainstem circuits regulating gastric function. Annu Rev Physiol 68:279-305.

Trussell LO (1999) Synaptic mechanisms for coding timing in auditory neurons. Annu Rev Physiol 61:477-496.

Ueta Y, Kannan H, Higuchi T, Negoro H, Yamaguchi K, Yamashita H (2000) Activation of gastric afferents increases noradrenaline release in the paraventricular nucleus and plasma oxytocin level. J Auton Nerv Syst 78:69-76.

Verberne AJ, Saita M, Sartor DM (2003) Chemical stimulation of vagal afferent neurons and sympathetic vasomotor tone. Brain Res Brain Res Rev 41:288-305.

Vincent A, Tell F (1997) Postnatal changes in electrophysiological properties of rat nucleus tractus solitarii neurons. Eur J Neurosci 9:1612-1624.

von Gersdorff H, Borst JG (2002) Short-term plasticity at the calyx of held Nat Rev Neurosci 3:53-64.

Wang ZJ, Rao ZR, Shi JW (1992) Tyrosine hydroxylase-, neurotensin-, or cholecystokinin-containing neurons in the nucleus tractus solitarii send projection fibers to the nucleus accumbens in the rat. Brain Res 578:347-350.

Wellman PJ (2005) Modulation of eating by central catecholamine systems. Curr Drug Targets 6:191-199.

Willing AE, Berthoud HR (1997) Gastric distension-induced c-fos expression in catecholaminergic neurons of rat dorsal vagal complex. Am J Physiol 272:R59-R67.

Zhang X, Renehan WE, Fogel R (1998) Neurons in the vagal complex of the rat respond to mechanical and chemical stimulation of the GI tract. Am J Physiol 274:G331-G341.

Zhu W, Pan ZZ (2005) Mu-opioid-mediated inhibition of glutamate synaptic transmission in rat central amygdala neurons. Neuroscience 133:97-103.

Zucker RS, Regehr WG (2002) Short-term synaptic plasticity. Annu Rev Physiol 64:355-405. 